\title{
EDER
}

\section{Educational Design Research}

\author{
Volume 3 | Issue 1 | 2019 | Article 20
}

\section{Contribution Type Academic Article}

Title Implementing an Intervention into a Grade Six Learning Environment: A Design-Based Research Framework

Author Deborah G. Lambert

University of Calgary

Canada

Michele D. Jacobsen

University of Calgary

Canada

Abstract Educators in some Canadian schools are especially challenged in developing innovative pedagogical approaches that can intellectually engage their students in deep learning of core curriculum content, while equipping them with 21st century competencies. In this paper, we discuss some key ideas on how an intervention, the design and building of digital video games, was implemented and explored, to address this challenge, in four grade 6 social studies classes at a Calgary charter school, utilizing a design-based research framework. Findings revealed that: (i) to effectively implement this intervention in the classroom context, teachers needed to shift/modify their design of instructional activities compared to how they would normally design them in their social studies classes to teach the same chosen content; and (ii) the intervention, as implemented, seem to have the potential to be an effective innovative pedagogy for deep learning and one that promotes the intellectual engagement of students and their development and application of 21st century competencies. Some implications of these findings for the implementation of interventions in school, in terms of transforming the classroom environment, assessing the type of theoretical support needed, using design-based research as an effective framework to study how interventions and developing policy for the implementation of interventions are listed for K-12 educators, school jurisdictions and Alberta Education. 
Keywords design-based research

innovative pedagogical approaches

deep learning

intellectual engagement

21st century competencies

digital video games

DOI dx.doi.org/10.15460/eder.3.1.1388

Citation Lambert, D.G. \& Jacobsen, M. D. (2019). Implementing an Intervention into a Grade Six Learning Environment: A Design-Based Research Framework. EDeR - Educational Design Research, 3(1), 1-36. http://dx.doi.org/10.15460/eder.3.1.1388

Licence Details Creative Commons - Attribution 4.0 International (CC BY 4.0) (c) (i) 


\section{Implementing an Intervention into a Grade Six Learning Environment: A Design Based Research Framework}

Deborah G. Lambert, Michele D. Jacobsen

\subsection{Introduction \\ $1.1 \quad$ Problem Statement}

Research has suggested that many students are "chronically bored in school - deeply, psychologically uninterested in formal education" (Millar, 2015) and seem "unimpressed with teachers' traditional didactic approaches or pre-packaged, depersonalised learning experiences" (Fullan \& Langworthy, 2014, p. 12). Research has shown that even with readily accessible digital and mobile technologies, a majority of instructional time in high schools, for example, comprises seatwork and whole-class instruction led by the teacher (Daniels, Jacobsen, Varnhagen \& Friesen, 2013; Jacobsen \& Friesen, 2011). Research also seems to suggest that students prefer learning by doing rather than being told what to do or just reading a textbook (Tapscott, 2009). Students want to be active, engaged and constantly connected with first-person learning (Junco \& Mastrodicasa, 2007) and are drawn from a community of young people who are engaged in gaming, multitasking and social networking (Jenkins, Clinton, Purushotma, Weigel \& Robison, 2006).

In light of these continued challenges, educators need pedagogical approaches that enable students to engage in experiences that connect their hearts, hands and minds for learning; experiences that allow them to experience the curriculum as something authentic, curriculum as generative ideas that they can "nudge about and look at from different sides, take apart, try out, become fascinated with ... try to reinvent" (Bereiter, 2002, p. 139). As such, educators are aiming to use innovative pedagogies that challenge students to learn in meaningful and authentic ways that intellectually engage learners in deep learning of curriculum content and ones that promote the development and use of 21st century competencies in school (Dunleavy et al., 2009; Fullan et al., 2014; Millar, 2015).

In this study, deep learning includes new knowledge creation and use, critical thinking skills, active and collaborative learning, emphasis on depth, negotiated formative assessment (Fullan \& Langworthy, 2014; West-Burnham \& Coates, 2005). Intellectual engagement includes "a serious emotional and cognitive investment in learning, using higher order thinking skills to increase understanding, solving complex problems" (Willms, Friesen \& Milton, 2009, p. 7), by learners who often lose track of time while absorbed, interested, curious and 
personally invested in work (Dunleavy, Milton \& Willms, 2012). Twenty-first century competencies include creativity and innovation, critical thinking, problem-solving and decision-making, communication, collaboration and teamwork, information literacy, living in the world (Binkley, et al., 2010).

In an effort to address this challenge, a design solution/intervention was proposed and implemented in four grade 6 social studies classes in a charter school in Alberta, Canada, to immerse and support learners in their learning of the decision-making method (consensus, representative democracy, majority and plurality voting) using a historical model of decision-making (Ancient Athens, Iroquois Confederacy, Municipal and Provincial [current era or modern day]) (Alberta Education, 2007).

The design solution/intervention, the design and building of digital video games, inherently employs relevant and well-known educational principles and supports all five learning capabilities, which include motor skills, attitude, verbal information, cognitive strategy and intellectual skills or Gagne's nine events of instruction (Gagne, Briggs \& Wager, 1992). It reflects learning environments that:

- students enjoy and are using outside the formal classroom context in "creative, entertaining and collaborative ways" (Jacobsen, 2010, A shifting Digital World, section, para. 3);

- teachers can use to create classroom-based "strong disciplinebased inquiry work [that] exhibits a number of very discernible characteristics" (Jacobsen, 2010, Teaching and Learning in the Digital Age section, para. 3), such as intellectually engaging in authentic tasks that demonstrate deep understanding of specified content through active participation in knowledge construction, while being equipped with 21st century competencies;

- $\quad$ provide for comprehensive and continuous work with ideas and practices that disrupt the established assumptions about teaching, learning and educational outcomes (Dunleavy et al., 2009);

- offer students greater control over their learning, while allowing them to participate in learning experiences that promote increased "peer interaction and access to [other students'] ideas, experiences, and knowledge" (Jacobsen, 2010, Effective Social Learning Online section, para. 6);

- offer "innumerable opportunities for students to find and join niche communities where they can benefit from the opportunities for distributed cognitive apprenticeship" (Brown \& Adler, 2008, p. 28), while allowing both teachers and students (at individual and community levels) to reflect on teaching practices and peer-topeer learning within and beyond the formal classroom context. 
The design-based research (DBR) process was used as a framework, to implement and explore this intervention guided by the following research questions: (i) In what ways do teachers' design of instruction and learning tasks need to shift when designing and building digital video games to intellectually engage students in deep learning of curriculum content and to develop and use 21st century competencies, in school? (ii) In what ways does the design and building of digital video games in school impact students' intellectual engagement, deep learning of curriculum content and the development and use of 21st century competencies? The theoretical framework that guided the implementation and exploration of the intervention follows.

\subsection{Theoretical Framework}

Herrington and Oliver's (2000) nine-element theoretical framework, guided the implementation and exploration of this intervention in the prototyping phase of the DBR process, and the evaluation of student intellectual engagement, deep learning and development of 21st century competencies. Table 1 offers a summary of how this framework informed this implementation and exploration.

Table 1

Theoretical Framework for Design, Implementation and Exploration of the Intervention in Prototyping Phase of the DBR Process.

Authentic context: The formal classroom context at a charter school in Calgary represented the game design learning environment as an authentic context that was all-embracing and collaborative, reflecting the ways that the knowledge constructed could be used in real-life and not separated from the noise, confusion, and group interactions prevalent in real work environments (Brown et al., 1989; Reeves \& Reeves, 1997).

Authentic activities: The leaming tasks' activities to promote the design and building of students'/groups' video games represented authentic and ill-defined game design and building activities (game concept development, storyboarding and programming) were implemented over a sustained period of time with real-world relevance (historical and modern day governments) (Brown et al., 1989; Reeves \& Reeves, 1997).

Access to expert performances and the modeling of processes: In this video game design and building environment, student participants continuously accessed and interacted with their teachers, who functioned as the curriculum content experts and designers of the student learning process. The student participants also interacted with their peers, many of whom were expert video game players and with some experience in building video games. Through this interaction with their peers, within and across groups, student participants were allowed to play various types of video games including those built in Scratch. Playing the Scratch games also allowed students to 'see inside' the games as they accessed the scripts, costumes and sounds to become familiar with how other video game designers coded/programmed their video games.

Multiple roles and perspectives: As teacher participants designed their instruction and the learning tasks' activities, they assumed multiple roles to allow them to design and implement their instruction from various perspectives (e.g., curriculum content experts and designers of the student learning process, facilitators, instructors, assessors, activators of student learning, collaborators, leaming coaches, reviewers and models). To participate in the leaming tasks, student participants were assigned specific roles (leaders, story writers, artists, musicians or sound engineers and programmers) which allowed them to explore and contribute their different perspectives to the design and building of their video games in an effort to communicate their understanding of how the citizens in their various models participated in the govemment decision-making process. 
Collaborative construction of knowledge: As teachers implemented the learning tasks, they became very involved in shaping and co-constructing ideas with the students/groups and each other in their effort to mainly promote a deep learning of how the citizens in students'groups' various models participated in the government decision-making process. As students participated and were actively engaged in all the learning ta sks, through student-student, student-group and group-group learning partnerships in their assigned roles, they also collaboratively created or developed new ideas or knowledge (game concepts, storyboards and game prototypes) in an effort to communicate their deep understanding on how the citizens in their various models participated in the government decisionmaking process.

Coaching and scaffolding: During the leaming tasks' activities, particularly in the game concept development and storyboarding tasks, teacher participants provided an extensive amount of coaching and scaffolding, through continuous formative assessments including discussions, "instructional conversations" (Tharp, Estrada, Dalton \& Yamauchi, 2000, p. 33) and Socratic dialogues/questioning, to students/groups in order to address any misconceptions they still had about the curriculum content, the solution of the given problem and the tasks' activities, and to offer suggestions for improvement. These suggestions were provided in the form of hints, reminders, feedback, modeling, scaffolding and fading.

Reflection: During their participation in the learning tasks' activities, students were given opportunities to reflect on their learning and knowledge-building experiences during the formative assessments with their teachers, peer assessments, within and across groups, in their kidblogs and in the interviews with the researcher. Through these reflections, the cognitive activities of abstracting, summarizing (Jonassen, Hartley \& Trueman, 1986; Rinehart, Stahl \& Erickson, 1986), and organizing Knowiledge (Kail, 1990) tended to promote their conceptual integration and retention of the govemment decision-making process in their various chosen models (Ancient A thens, Iroquois Confederacy, Municipal and Provincial [current era or modem day]). During their implementation of the leaming tasks, the two teacher participants collaboratively reflected on the design of their instruction and leaming tasks' activities, their contribution to student leaming and their professional leaming in challenging their methods of assessment, in particular. In some instances, the teachers also collaboratively reflected on student performance and their implementation of some tasks' activities with the professional development leader.

Articu lation: Student participants, in collaboration with their teachers and peers, articulated, negotiated, discussed and defended their game concept and storyboarded ideas and game prototypes in an effort to communicate their deep understanding of how the citizens in their various models participated in the government decision-making process.

Integrated authentic assessment: Throughout their implementation of the learning tasks, particularly, the game concept development and storyboarding tasks, the teacher participants deliberately developed and integrated various assessment practices and approaches that reflected the context and the nature of their students and ensured that the students were a part of these assessments. These included: (i) assessments for their learning (formative assessments - weekly assignments, instructional conversations, discussions, Socratic dialogues/questioning, which also involved a great amount of coaching and scaffolding, with feedback loops involving large amounts of descriptive feedback) to assess their progress and to inform the modifications or refinement to their work; (ii) assessments as their learning (self and peer assessments-Let's Reflect rubric, students'groups' reflections in their Kidblogs, elevator pitches and group-share reflections with feedback for improvement); and (iii) assessments of their learning (summative assessment of students' achievement of the leaming goals at the end of the process)

\subsection{Implementation of the Design Solution/Intervention Using the}

\section{DBR Framework}

The DBR framework informed by McKenney and Reeves' (2012) micro, meso- and macro-cycles in educational design research (Figure 1) informed the implementation of the intervention to immerse and support learners in learning how the Athenians, Iroquois and modern day citizens used decision-making methods (consensus, representative democracy, majority and plurality voting) to participate in the government decision-making process (Alberta Education, 2007). For the purpose of this study, DBR is defined as "a systematic but flexible methodology aimed to improve educational practices through iterative analysis, design, development, and implementation, based on collaboration among researchers and practitioners in real-world settings, and leading to contextually sensitive design principles and theories" (Wang \& Hannafin, 2005, p. 6). 


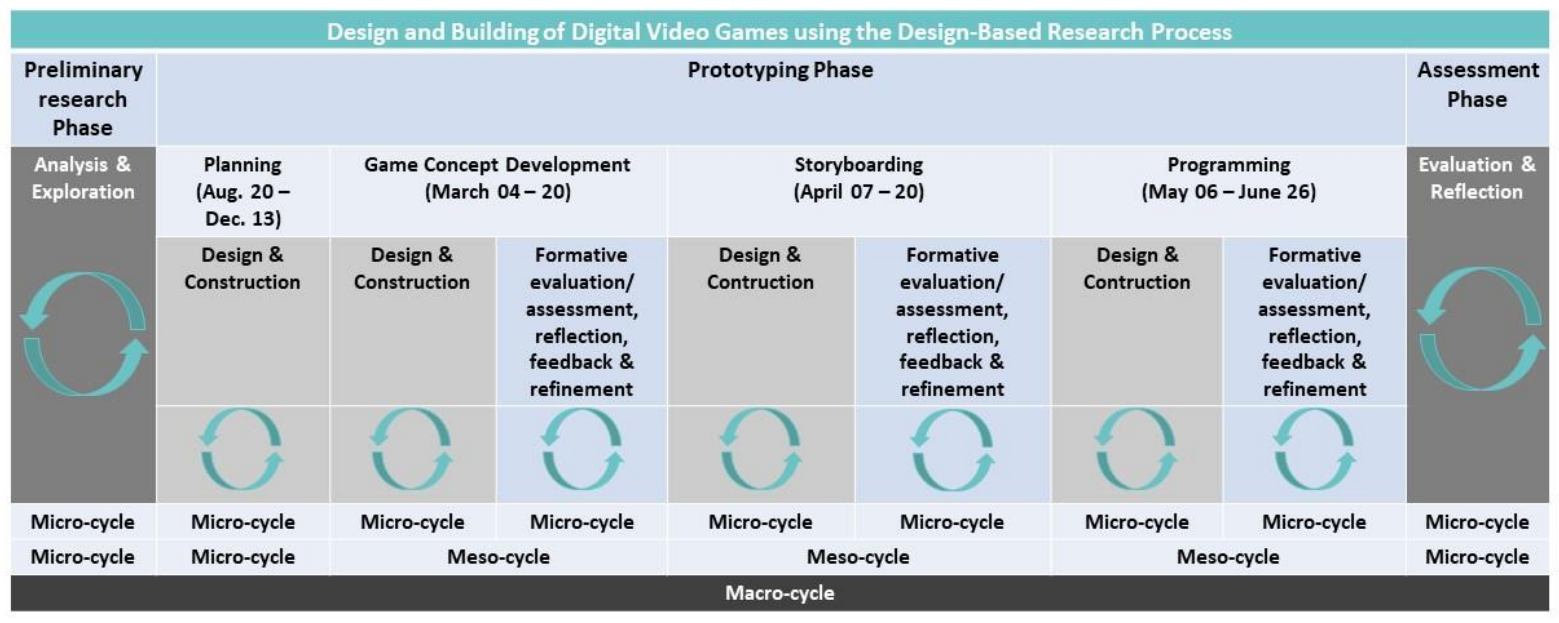

Figure 1. Implementation of the design and building of digital video games in macro-cycle of the design-based research process adapted from McKenney and Reeves' (2012) micro, meso- and macro-cycles in educational design research.

This macro-cycle of the entire DBR process (McKenney \& Reeves, 2012) comprised one micro-cycle of the preliminary research or analysis and exploration phase, during which the intervention was adopted into the educational context; one micro-cycle and three meso-cycles (six micro-cycles) of the prototyping phase, during which the intervention was explored; and one micro-cycle of the assessment or evaluation and reflection phase, during which the intervention was assessed as a potential and effective innovative way or pedagogy that can also possibly address the questions guiding this research.

Participants. The implementation of the design and building of digital video games was carried out by a research team at a charter school in Alberta, Canada. This team comprised immersed researcher/designer/observer/participant, two grade six Social Studies practitioners/designers (teaching social studies for 3 and 16 years, and with no experience in playing or building video games), a professional development leader (a former grade 7 social studies teacher with some experience in playing and building video games), who provided their consent, one hundred grade six students, from whom the researcher obtained assent, their parental consent and an external advisor. Ninety-seven ( 59 were males and 38 females) of the 100 students had played various video games, while twenty-one (17 were males and 4 females) had some experience building video games, mostly using game software such as SketchNation. To participate in the learning tasks, students were assigned specific roles (leaders, story writers, artists, musicians or sound engineers and programmers), which allowed them to explore and contribute their different perspectives to the design and building of their video games in an effort to communicate their understanding of how the citizens in their various models participated in the government decision-making process. 
Data collection. DBR interventions are assessed using multiple methodologies (Anderson \& Shattuck, 2012). As such, a mixedmethods embedded design (Creswell, 2014) was employed before, during and after the prototyping phase, to sequentially collect data (listed in Figure 2) that would guide the implementation of the intervention. Specifically, before the prototyping phase, quantitative and qualitative data - online surveys (students' and teachers' video game experience; students' learner profiles) and pre-interviews (teachers' current instructional strategies in social studies; opinions of students' learning characteristics; students' opinions on how they learned and prefer to learn social studies) - were collected. During and after the prototyping phase, priority was given to the collection of qualitative data (participants' experiences during and after the learning tasks' activities) supported by the collection of quantitative data emanating from the qualitative data. This sequential form of data collection aimed to collect multiple sources and types of data that were congruent with the research questions.

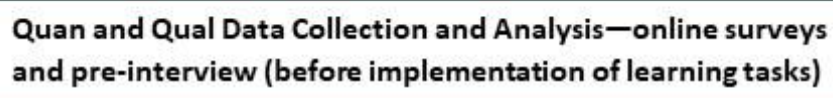

Figure 2. Adapted embedded design from Creswell (2014) mixed-methods designs employed to collect data.

Since design-based researchers need to be immersed in the research context and intensely collaborate and interact with their participants throughout the research process, achieving objectivity can be a challenge when conducting design-based research. Therefore, the triangulation of multiple sources and types of data was purposeful and intentional in order to maintain and increase the objectivity of the findings, contribute to improved reliability of the findings, as well as address possible bias and add depth and increase rigor to the research process (Anderson \& Shattuck, 2012; McKenney \& Reeves, 2012; Wang \& Hannafin, 2005).

Data analysis. The collected data was analyzed, systematically and continuously, to inform preparation for the prototyping phase and possible refinement or iterations of the learning tasks during that phase. To carry out the analysis of the collected data, a framework analysis (Ritchie \& Spencer, 1994) was adapted using four of the five 
key stages of this form of analysis including familiarization, identifying a thematic framework, indexing, mapping and interpretation, aided by visual displays and plots (Lacey \& Luff, 2001). The practitioners' and students' emerging experiences were also analyzed by adapting Moustakas' (1994) development of textual description - the 'what' not the 'why' of their experiences to identify and describe rich accounts of the ways in which teachers needed to shift their design of instruction and learning tasks and students' design and building of their video games for students' intellectual engagement in deep learning of how the citizens in their various models participated in the government decision-making process and development and use of 21st century competencies. Guided by the principle of DBR for the analysis of collected data, during and at the end of the three learning tasks, the collected data was "analyzed immediately, continuously, and retrospectively" (Wang \& Hannafin, 2005, p. 17) on an ongoing basis. A discussion of the actual implementation of the intervention using the three core phases of the DBR process as a framework follows.

\subsection{Preliminary Research Phase - Analysis and Exploration}

The preliminary research phase or analysis and exploration phase is the initial phase of the DBR process, which "constitutes one (empirical) micro-cycle [and] includes problem identification and diagnosis" (McKenney \& Reeves, 2012, p. 79). It is at this phase that Amiel and Reeves (2008) suggest that DBR should begin with "the negotiation of research goals between practitioners and researchers ... in establishing research questions and identifying problems that merit investigation" (p. 35). In this research study, however, establishing the research questions and identifying and discussing the problem supported by a review of the literature to understand and contextualize the problem took place before the researcher reached out to three grade 6 practitioners.

Collaboration with the practitioners began by presenting them with the goal of the research, a statement of the problem, a proposed research-informed design solution for the problem - an intervention, the design and building of digital video games and the rationale for choosing it as a solution to the problem. We also reviewed the literature on the game design-based learning context, the theoretical framework to support the design and implementation of the intervention into the classroom context, the research questions that guided the study, the observational protocols to guide the researcher's initial direct observation of the prototyping phase of the process and some literature on the DBR methodology. As recommended by David Reinking, this presentation and conversation helped to vet the practitioners on the background of the research and to ensure that they would be collaborative and open to the research process as their shared commitment to solving the identified problem around practice was of critical importance to the research (LiteracyResearch, 2014). 
In considering the design solution/intervention, one practitioner expressed his concern about the benefits of its implementation to their students' learning, in terms of helping to deepen students' understanding of the curriculum content. "Understanding the concerns of those who will use interventions created through educational design research is essential to shape both design and implementation" (McKenney \& Reeves, 2012, p. 174). Therefore, to help address this concern, we reviewed and discussed the proposed intervention and how it could be implemented and explored to intellectually engage their students in deep learning of chosen social studies content, while equipping them with 21st century competencies. The design of the proposed intervention was based on an assessment of the problem identified and informed by relevant game design-based literature, learning theories, specifically, Herrington and Oliver's (2000) nine characteristics of the evolving theory of situated learning environments, which formed the theoretical framework (Table 1) and game design principles adapted from Mellini, Talamo and Giorgi's, (2010) embedded educational characteristics of gaming, learning and technical aspects (Table 5).

Subsequent to a review and discussion of the proposed intervention, the practitioners modified it (first iteration) based on their students' learning needs and their teaching goals (Table 2) and were willing to adopt it to help their students learn and communicate a deeper understanding of how the Athenians, Iroquois and modern day citizens used decision-making methods to participate in the government decision-making process, while becoming more intellectually engaged in their learning and developing 21st century competencies. The main difference between their version and the proposed version appeared in the statement of the learning goals, the specified curriculum content that the students needed to learn and understand during the intervention, and the practitioners' expectations of student performance informed by formative and summative assessments.

Table 2

Collaborative Framework by Practitioners and Researcher

\begin{tabular}{lll}
\hline \multicolumn{2}{c}{ Collaborative Framework for the Design and Implementation of the Design and Building } \\
of Digital Video Games
\end{tabular}




\begin{tabular}{|c|c|c|}
\hline Phases & Stages & Time-frame \\
\hline & $\begin{array}{l}\text { Storyboarding } \\
\text { - Problems to be solved in story/content design } \\
\text { Find possible contexts that might be appealing for the potential audience of the } \\
\text { digital video games } \\
\text { - Teams select a real-life situation(s) that embed the content and the context defined } \\
\text { in the previous steps } \\
\text { - Story to be drafted from specified content and for specific contexts informed by } \\
\text { research } \\
\text { - Artwork to be drafted to support story/content in specific contexts } \\
\text { Music/sounds to be created to support games } \\
\text { Teachers design and develop assessment of group performance (rubrics); formative } \\
\text { assessment; blog reflections and provide feedback to corroborate the learning } \\
\text { process involved in student participants' games to intellectually engage them in } \\
\text { deep learning of the content provided and their acquisition of core } 21^{4} \text { century } \\
\text { competencies } \\
\text { - Conduct correspondence analyses to confirm whether initial ideas and models have } \\
\text { the potential to propose solutions to the given problem } \\
\text { - Ensure that the game situation(s) matches the proposed content and the game } \\
\text { design principles informed by Mellini, Talamo and Giorgi's (2010) educational } \\
\text { characteristics of gaming, learning and technical aspects of game design }\end{array}$ & $\begin{array}{l}6 \text { weeks } \\
\text { (March 20- } \\
\text { May 1, 2014) }\end{array}$ \\
\hline $\begin{array}{l}\text { Phase 4: } \\
\text { Building core } \\
\text { mechanics } \\
\text { (iterative) } \\
\text { Packaging } \\
\text { (Reflection and } \\
\text { Evaluation) }\end{array}$ & $\begin{array}{l}\text { Programming } \\
\text { Prototype design informed by game design principles informed by Mellini, Talamo } \\
\text { and Giorgi's (2010) educational characteristics of gaming, learning and technical } \\
\text { aspects of game design } \\
\text { Content refinement } \\
\text { - Prototype refinement } \\
\text { Ensure that the game situation(s) matches the proposed content and the game } \\
\text { design principles } \\
\text { - Confirm that each of the core and the processing components successfully support } \\
\text { one another } \\
\text { Based on the correspondence analyses, student participants make the necessary } \\
\text { changes and presented the final design of the game }\end{array}$ & 6 weeks \\
\hline
\end{tabular}

Adapted from, and informed by Hung's (2006) 3R3C model of problembased learning environments

The practitioners' input was critical to the design of the framework because they were more knowledgeable about their students' learning needs, the context (including the nature of their students) within which the implementation of the intervention would take place and the learning and teaching goals they wanted to achieve in exploring this intervention. Having achieved a shared understanding of the intervention, its possible benefits for their students' learning, and constraints to its implementation, we implemented our collaborative framework, which was further modified (second iteration) to meet the learning and intervention goals of the research process (Figure 3).

\subsection{Prototyping/Development Phase - Design and Construction}

In design-based research, the prototyping or development of solution phase or design and construction phase is the iterative design phase consisting of iterations, each being a micro-cycle of research, mostly through exploration, with formative evaluation as the most important research activity aimed at improving and refining each stage of an intervention (McKenney \& Reeves, 2012). In this research study, the intervention was implemented and explored (approximately eight months) in one planning task and three learning tasks - game concept development, storyboarding and programming, as shown in Figure 3. 

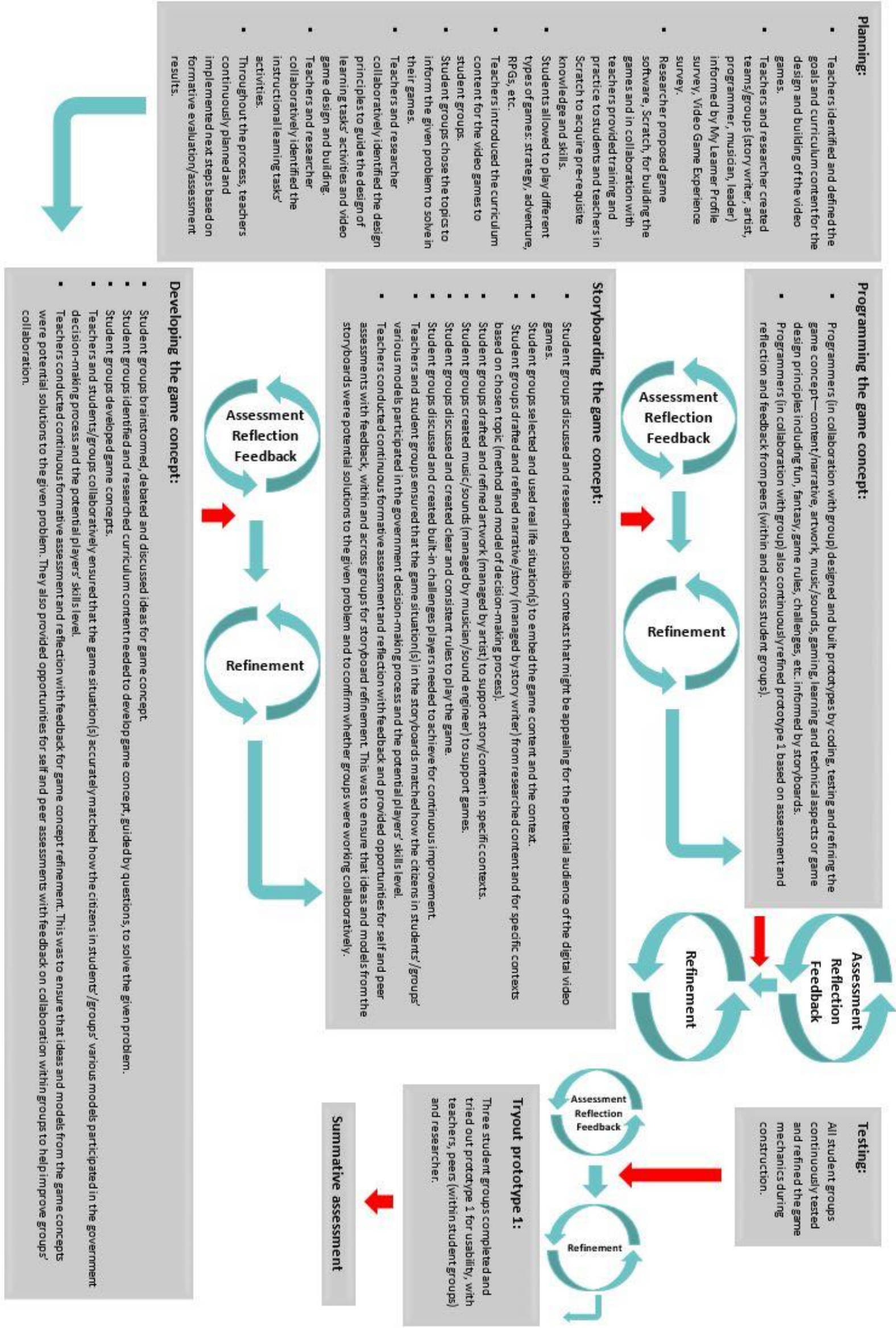
The planning task represented one micro-cycle of design and construction of the task's activities (Figure 3). To initiate this task, the practitioners, in collaboration with the researcher, identified and defined the curriculum content-specific learning goals for the intervention: (i) to recognize how individuals and governments interact and bring about change within their local and national communities; (ii) to demonstrate an understanding of the fundamental principles of democracy; and (iii) to analyze the structure and functions of Alberta's provincial government (Alberta Education, 2007). They also identified the curriculum content that should inform the domain knowledge of students'/groups' video games as they tried to solve the given problem, 'How did/do the citizens participate in the decision-making process?' to achieve the learning goals. The specific areas of the curriculum content identified included: decision-making method (consensus, representative democracy, majority and plurality voting) using a historical model of decision-making (Ancient Athens, Iroquois Confederacy, Municipal and Provincial [current era or modern day]) (Alberta Education, 2007).

Then, in collaboration with the researcher, the practitioners created twenty student groups (five students in each group comprising a story writer, artist, musician/sound engineer, programmer, leader) within which the students could collaboratively construct their knowledge/ideas as they designed and built their video games. The story writer was responsible for creating and managing the stories and dialogues that would inform their game concepts. The artist was responsible for designing and managing all the artistic aspects of the game including the graphics, textures, backgrounds, models, characters and animations. The musician/sound engineer was responsible for creating sounds and background music for the scenes in the game. The programmer was responsible for building (coding, scripting, testing, refining) the game prototypes. The leader was responsible for managing the group's activities and ensuring that group members remained on task.

In order to acquire some pre-requisite knowledge and skills in preparation for the actual design and building of the video games during the learning tasks' activities, the students and practitioners participated in formal training and practice sessions in the use of the chosen game software, Scratch, over a four-week period. Training videos on Scratch were uploaded on Edmodo, the learning Management System (LMS), for easy access within and beyond classroom sessions. This was critical to the process since both practitioners and $79 \%$ of student participants in the Video Game Experience survey indicated that they had no experience in building digital video games. Students were also allowed to play various types of video games including those built in Scratch. Whilst playing the Scratch games, they were also encouraged to 'see inside' the games by accessing the scripts, costumes and sounds to become familiar with 
how other video game designers coded and scripted their games. The training period helped to stimulate the students' enthusiasm for designing and building these video games, which needed to be carried over to the actual design and building of their games during the learning tasks. For practitioners, especially, the training and practice with Scratch helped to support their intended instructional activities.

\subsubsection{Learning tasks}

The learning tasks - game concept development, storyboarding and programming - represented three meso-cycles of design and construction of the learning tasks' activities informed by a formative evaluation/assessment, reflection, feedback and refinement strategy (Figure 1). Practitioners used this strategy to inform their designed instruction in an effort to promote the effectiveness of the learning tasks to meet the learning and intervention goals, particularly, the game concept development and storyboarding and to assess students'/groups' progress. In the programming task, a modified form of this strategy was used mostly by the students/groups, as practitioners took a more hands-off approach during this task. The practitioners' design and construction of each learning task were informed by instructional activities (Table 3 ), instructional design principles (Table 4) and game design principles (Table 5) to generate "successive approximations of the desired solution" (McKenney \& Reeves, 2012, p. 79) to the problem. These approximations or iterations were informed by the results of the formative evaluation/assessments, reflections and refinements, as well as some of the findings from the continuous analysis of collected data for the research.

Table 3

Instructional Activities

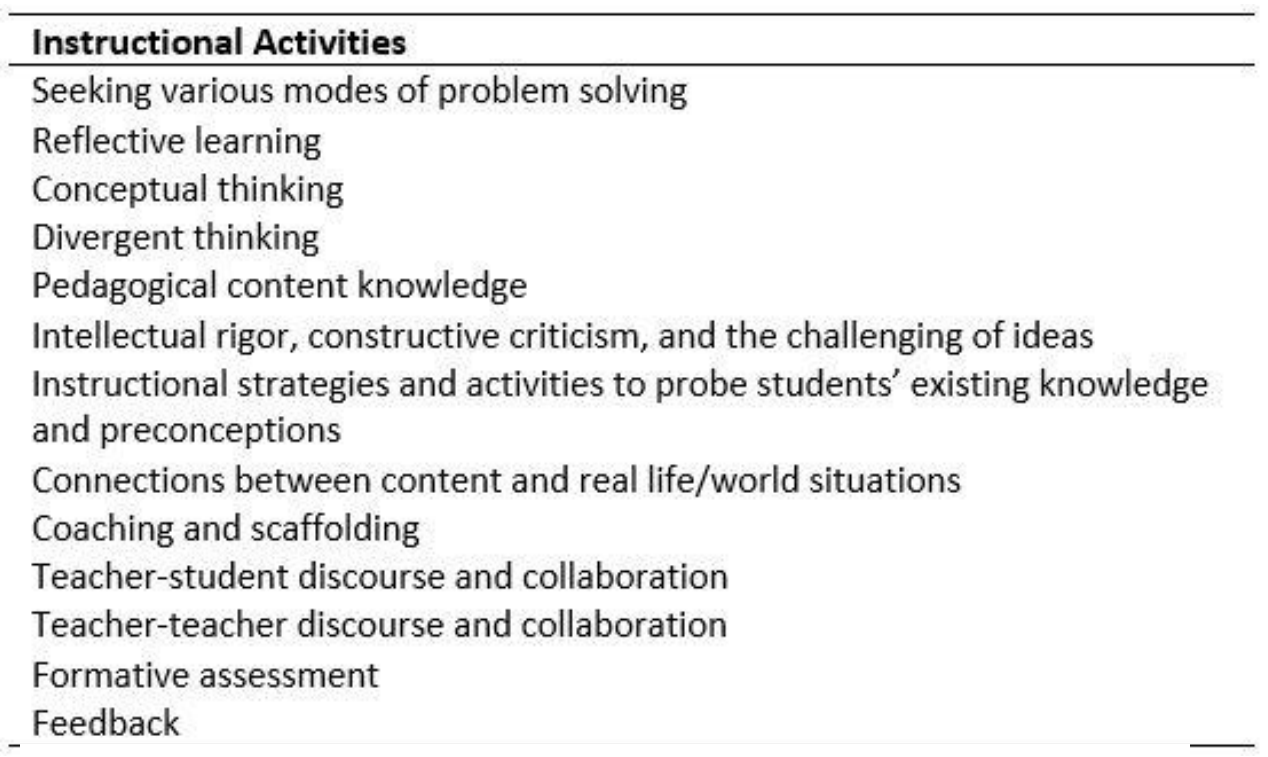

Adapted from Flick, Morell and Wainwright's (2002) OCEPT-Teacher

Observation Protocol (O-Top) 
Table 4

Instructional Design Principles to Guide Learning Tasks'

Activities/Ideas

DESIGN PRINCIPLES

ANCHORED Students allowed to define and investigate problem or given information;

INSTRUCTIONAL students allowed to experience the given problem from a number of different

ACTIVITIES perspectives; students working on the problem over a sustained or 'reasonably

long period of time', that is weeks rather than days; activities should be

logically related to the problem to be investigated (Bransford, Vye, Kinzer \&

Risko, 1990; Herrington \& Reeves, 2011)

CLIMATE FOR

Students are provided opportunities to clarify the understanding of their ideas

REFLECTION

through reflection; time is provided to reflect and work on solving the problem (Boud \& Knights, 1996; Herrington \& Reeves, 2011)

DESIGN AND DEVELOPMENT

OF WEB-BASED MLATERLALS

USING NEIV TECHNOLOGIES

CULTURALLY INCLUSIVE INSTRUCTIONAL DESIGN
Chosen meaningful contexts for the learning of the curriculum content; support and a variety of resources provided; use of authentic assessment activities (Herrington \& Reeves, 2011; Oliver, 2000)

Epistemology that is consistent with, and supportive of constructivist learning adopted; designed authentic learning activities; flexible tasks and tools for knowledge sharing created; different forms of support provided within and outside the classroom community; flexible and responsive student roles and responsibilities established; communication tools and social interaction for learners to co-construct knowledge provided; tasks for self direction, ownership and collaboration created; flexible tutoring and mentoring roles that are responsive to learner needs provided; access to varied resources to ensure multiple perspectives created and provided; flexibility in outcomes and modes of assessment provided (Herrington \& Reeves, 2011; McLoughlin \& Oliver, 2000)

Table 5

Game Design Principles: Specific Details of Embedded Educational Characteristics of Gaming, Learning and Technical Aspects

\begin{tabular}{|c|c|}
\hline \multicolumn{2}{|c|}{ Educational Characteristics in Gaming Aspects } \\
\hline Goals & $\begin{array}{l}\text { The goals and objectives that the game designer and/or player will need to } \\
\text { accomplish in an effort to complete the targeted game should be clearly specified and } \\
\text { presented. }\end{array}$ \\
\hline Rules & $\begin{array}{l}\text { The game's rules should be dear and consistent throughout the game. This will help } \\
\text { the game designers and/or players achieve the goals and objectives they have to } \\
\text { accomplish in order to successfully complete the game. }\end{array}$ \\
\hline Challenge & $\begin{array}{l}\text { To strive for continuous improvement, the game designer and/or player should be } \\
\text { continuously challenged by increasing the level of difficulty throughout the game. } \\
\text { However, to avoid discouraging the game designer and/or player, the level of } \\
\text { possibilities should outweigh the level of challenge. }\end{array}$ \\
\hline $\begin{array}{l}\text { Rewarding } \\
\text { system/short } \\
\text { feedback cycle }\end{array}$ & $\begin{array}{l}\text { In order to be able to continuously assess their performance and to modify } \\
\text { or change their actions, game designers and/or players should be able to perceive the } \\
\text { results of their actions as they design and/or play the game. Rewards are usually } \\
\text { associated with positive results and can help to motivate the designer and/or player to } \\
\text { achieve the game's objectives, while also increasing their level of engagement and } \\
\text { immersion in the game. }\end{array}$ \\
\hline $\begin{array}{l}\text { Engagement/ } \\
\text { immersion }\end{array}$ & $\begin{array}{l}\text { Various techniques, such as goals that are challenging, context, appealing } \\
\text { environments, interesting story lines should be used to engage the game designer } \\
\text { and/or player. }\end{array}$ \\
\hline $\begin{array}{l}\text { Adaptability/ } \\
\text { flexibility }\end{array}$ & $\begin{array}{l}\text { For each game designer and/or player to achieve adaptability in the game experience, } \\
\text { challenges should be varied according to the designer's and/or player's knowledge } \\
\text { and skills. }\end{array}$ \\
\hline Re-playability & The game designer and/or player should be able to play the game multiple times. \\
\hline $\begin{array}{l}\text { Competition/ } \\
\text { collaboration }\end{array}$ & $\begin{array}{l}\text { Healthy competition and collaboration between game designers and/or players } \\
\text { should be promoted in the game scenario. }\end{array}$ \\
\hline Entertainment & The game needs to be entertaining to the game designer and/or player. \\
\hline
\end{tabular}

table continues 


\begin{tabular}{|c|c|}
\hline \multicolumn{2}{|c|}{ Educational Characteristics in Learning Aspects } \\
\hline $\begin{array}{l}\text { E ducational } \\
\text { objectives }\end{array}$ & $\begin{array}{l}\text { The educational objectives of the game or its design should be dearly defined to } \\
\text { allow students/game designers/players to achieve the educational affordances of the } \\
\text { game. }\end{array}$ \\
\hline Students' profile & $\begin{array}{l}\text { When designing the game scenario, the students'/game designers'/players' age } \\
\text { level, knowledge and skills and socio-cultural background should be considered. }\end{array}$ \\
\hline $\begin{array}{l}\text { Learning } \\
\text { resources }\end{array}$ & $\begin{array}{l}\text { In achieving the educational objectives of the game, relevant leaming resources } \\
\text { should be provided within the game or as links to the game. }\end{array}$ \\
\hline Personalization & $\begin{array}{l}\text { The game leaming and design process could be more personalized based } \\
\text { on the students' age, previous knowledge, skills and the speed at which } \\
\text { they acquire new knowledge and skills. }\end{array}$ \\
\hline $\begin{array}{l}\text { E valuation } \\
\text { methodologies }\end{array}$ & $\begin{array}{l}\text { In the game learning/design scenario, an evaluation or assessment method specific } \\
\text { to the game context could be considered. For instance, instead of traditional } \\
\text { approaches such as exams, a rewarding system with immediate feedback loops } \\
\text { could be used to evaluate or assess the students'/game designers"/ players' } \\
\text { performance in designing and playing the games. The feedback loops will help the } \\
\text { students'/game designers'/ players' to continuously check their progress. }\end{array}$ \\
\hline $\begin{array}{l}\text { Comprehensive } \\
\text { learning scenario }\end{array}$ & $\begin{array}{l}\text { Other learning activities, such as classroom discussion sessions, re flection sessions, } \\
\text { group activities, reports and so on, can be embedded in a game-based learning } \\
\text { scenario. }\end{array}$ \\
\hline $\begin{array}{l}\text { Progressive } \\
\text { acquisition of } \\
\text { knowledge }\end{array}$ & $\begin{array}{l}\text { During their learning experience in the game-based leaming scenario, } \\
\text { the students/game designers players should be challenged at a level } \\
\text { high enough to engage and motivate, but not frustrate them. }\end{array}$ \\
\hline $\begin{array}{l}\text { Level of autonomy } \\
\text { of the learner }\end{array}$ & $\begin{array}{l}\text { Depending on the educational context, the students'/game designers' /players' } \\
\text { autonomy-allowing them to explore the game without the teacher's intervention, } \\
\text { should be predefined. }\end{array}$ \\
\hline Motivation & $\begin{array}{l}\text { Students'/game designers'/players' motivation to participate in the game design and } \\
\text { playing activities is critical to achieving the educational objectives of game-based } \\
\text { leaming. Motivation, here, will be grounded in Csikszentmihalyi's (1990) Flow } \\
\text { Theory to provide enjoyment or pleasure in the game design building and playing } \\
\text { activities. Csikszentmihalyi identifies the following characteristics of flow that are } \\
\text { consistent with effective games: every step of the way has clear goals, feedback on } \\
\text { the designers' and/or players' actions is immediate, challenges and skills are } \\
\text { balanced, awareness and action are merged, distractions are excluded, failure is not } \\
\text { a concem, self-consciousness is absent, there is no sense of time and the activity is } \\
\text { an end in itself (Rieber, 1996). }\end{array}$ \\
\hline \multicolumn{2}{|c|}{ Educational Characteristics of T echnical A spects } \\
\hline Usability & $\begin{array}{l}\text { The game should be easy to design and played so that the designer and/or player } \\
\text { can focus on the objectives of the game without being overwhelmed or frustrated. } \\
\text { The functionalities of the game should be easy to design and leam. Interactions } \\
\text { within the game context should be clear with little to no glitches in navigation. }\end{array}$ \\
\hline $\begin{array}{l}\text { Well-designed } \\
\text { graphics }\end{array}$ & $\begin{array}{l}\text { In order to engage and motivate user, the visual aspects of the game should be real } \\
\text { and attractive. }\end{array}$ \\
\hline Re-usability & $\begin{array}{l}\text { B ecause of the adaptation potential of games (both in design and play), their re- } \\
\text { usability level is high and can be used in various contexts with diverse groups of } \\
\text { students/designers/players. }\end{array}$ \\
\hline
\end{tabular}

Adapted from Mellini, Talamo \& Giorgi's (2010) Fostering Teachers ' Creativity through Game-Based Learning (pp. 23-22)

\subsubsection{Game concept development task}

The main goal of the game concept development task was for students to develop a game concept that would achieve the learning goals as they demonstrated their deep understanding of their chosen topics, while providing the target game players with a 'learn as you go' experience. The game concept was based on the problem, "How $\mathrm{did} /$ do the citizens participate in the decision-making process?" and embedded in a narrative/storyline that a player needed to follow in order to solve the problem. To develop that game concept, the practitioners presented all groups with the following plan (Figure 4). 
Choose and discuss decision- making method and decision- making model to solve problem:

'How did/do the citizens participate in the decision-making process?'

Group's decision to be approved by teachers.

Blog about how group decided on chosen topics and models including experiences in collaborating on this task.

Create guiding questions that will drive research on the decision-making method and model chosen. Guidelines to formulate effective guiding questions and examples posted in Edmodo for student groups to reference while collaborating on this task.

As an assignment, submit guiding questions through Edmodo for teacher feedback and approval.

Upon approval by teachers, groups to use guiding questions to compile the research on chosen decision-making method and model to solve problem.

As an assignment, groups to reflect on group's performance in research process guided by the question: "How did the members of your group perform during this stage?" Teachers would assess group reflections and provide feedback by considering the following attributes in a reflection rubric: Cooperation, Contribution, communication and Collaboration.

Brainstorm possible stories with game potential from research content gathered from guiding research questions. Characteristics of a great story in game creation provided in Edmodo for guidance to create storyline.

Finalize game concepts.

Figure 4. Initial game concept development plan

To initiate and throughout the duration of the game concept development task, the practitioners collaboratively held introductory 15-minute teaching moments with two classes per session (50 students) to describe, clarify and provide feedback on the task's activities that had to be completed to develop the game concepts. In the first two sessions of this task, as instructed, students/groups collaboratively chose their decision-making methods and models as well as began formulating the questions to guide the research for the content that would help solve the problem. Though all the groups had successfully chosen their decision-making methods and models, which were approved by their teachers, it had become evident from their blogs, practitioners' and researcher's observations that group collaboration seemed difficult for most of the groups and it appeared to be adversely affecting the groups' abilities to effectively perform their activities. For instance, students within their groups seemed to encounter challenges in: building respectful, caring and effective relationships to manage conflict and differences, and to seek consensus in the pursuit of common goals; accepting responsibility for their actions as individuals; using their influence and powers responsibly; keeping the interests of the group in mind.

Therefore, in sessions three and four, after formatively evaluating the students'/groups' collaborative issues, in collaboration with the researcher, the practitioners chose to pause the group work focused on developing the guiding questions for groups' research on their topics and instead, aimed to assess group performance earlier in the task, which resulted in the refinement or re-design of the initial sequence of the task's activities or first iteration of this task. The practitioners utilized their co-constructed reflection rubric, Let's 
Reflect, to allow group members to self and peer reflect on performance and progress within the group, guided by the following four attributes (Table 6):

Table 6

Let's Reflect: Reflection Rubric

\begin{tabular}{ll}
\hline Attributes & Questions \\
\hline Cooperation & $\begin{array}{l}\text { Do your group members work well together? } \\
\text { Do you find solutions when problems arise? }\end{array}$ \\
Contribution & $\begin{array}{l}\text { Do your group members participate in the process? } \\
\text { Is each group member "pulling their weight?" }\end{array}$ \\
Commumication & $\begin{array}{l}\text { Do your group members express their ideas? } \\
\text { Do your group members listen to and consider the ideas of others? }\end{array}$ \\
& $\begin{array}{l}\text { Do your group members combine ideas to create stronger ones? } \\
\text { Collaboration }\end{array}$ \\
\end{tabular}

The teachers explained to the students that it was necessary to carry out this reflection at this point because without the effective collaboration of groups, it would become even more challenging to complete their activities and to effectively learn from the process of this task or this experience as they attempted to design and build their games.

During the reflection sessions, all of the groups completed and submitted their reflections to their teachers, who provided constructive feedback to each group. To address specific issues, for example, in cooperation, contribution, communication and collaboration, practitioners and group members in each group discussed the results of the reflections and collaboratively suggested ways to address issues that were inhibiting the ability of the group to effectively collaborate and work on task activities. The practitioners also invited the school's principal to provide and discuss with students some beyond school-life experiences on the importance of collaboration to their development and in preparation for the world of work and adult life roles. Subsequent to this assessment, collaboration within all the groups seemed to steadily improve as the process continued.

By sessions five and six, all groups were re-focused on developing their guiding questions to inform the research of the chosen topics, with the intent to inform the game concepts. At the start of each of these sessions, using a 15-minute teaching moment, the teachers reviewed some characteristics of effective guiding questions with all the groups and provided them with examples of effective guiding questions, which they also posted in Edmodo for student reference. They explained to the students/groups, that the goal was to have them engaged in actual research and not simple 'fact finding'.

As the students/groups posted their questions in Edmodo, it also became evident to both practitioners and researcher that formulating 
these questions were proving to be very challenging to most of the groups. The questions formulated did not inform their research and they seemed unclear about the depth of the questions, thus making it difficult to determine the depth of the research that needed to be carried out on their topics. As a result, practitioners and researcher collaboratively engaged in some formative evaluation of this issue and realized that the students/groups needed more guided instruction on this activity than initially planned and given. Therefore, in sessions seven and eight, the practitioners refined the activity by reviewing the formulation of effective guiding questions with all groups, resulting in the second iteration of this task. They first used examples of questions that some groups had formulated to coach students/groups in modifying their questions informed by the following characteristics of effective guiding questions (Table 7).

Table 7

Characteristics of Effective Questions

Characteristics of Effective Questions

- A guiding question addresses the "heart of the discipline ' being studied. Essential disciplinary knowledge will be required to answer it.

- A guiding question is open-ended, possible to contend, arguable. It must be complex enough to house multiple perspectives and possible answers.

- A guiding question possesses emotive force, intellectual bite, or edginess. Students should be able to engage in quality discussions about the topic.

- A guiding question may lead to new que stions asked by the students (Wilhelm, 2007)

Who Cares Test - Moving Beyond Simple Information Gathering to Higher-Level Questioning

1. How is --related to?

2. What is a new example of

3. What are some possible solutions for the problem of

4. Explain why

5. What do you think would happen if -

6. Why is - - important?

The practitioners also discussed and coached all groups on how to use their guiding questions to brainstorm ideas for their narratives/storylines to also inform the research needed to develop the game concepts. However, through their discussions with the students/groups, students' reflections in their kidblogs and documented guiding questions and storyline ideas in students'/groups' Google documents, almost all the groups seemed to have difficulty matching their guiding questions to their narrative/storyline ideas.

Based on these findings, practitioners and researcher discussed and formatively evaluated the difficulty experienced by many of the groups in an effort to develop strategies to address this learning need. We agreed that the sequence in formulating the questions, carrying out the research and then brainstorming the narrative/storyline ideas seemed to be contributing to this difficulty. Groups were initially attempting to formulate questions with no idea of what their narratives/storylines would be about - ideas through which they could creatively solve the problem in their games. 
The questions were formulated primarily to carry out general research on the topics rather than in connection to a narrative/storyline. This seemed to be an overwhelming task for the students/groups and it resulted in some frustration with the activity. In further discussing this issue, the practitioners and researcher realized that the students/groups seemed to have no context within which to frame the given problem so they could creatively address it in a story. Therefore, in agreement, the practitioners decided to refine or re-design the sequence of the task's activities, resulting in the third iteration of this task. Students/groups were instructed to first brainstorm some ideas for the narratives/storylines on how the citizens in their various models participated in the government decision-making process, then develop questions that would help them to research the content to inform these narrative/storyline ideas. As students/groups worked with this refined sequence of the task, the practitioners assessed each group using a formative assessment strategy (Figure 5).

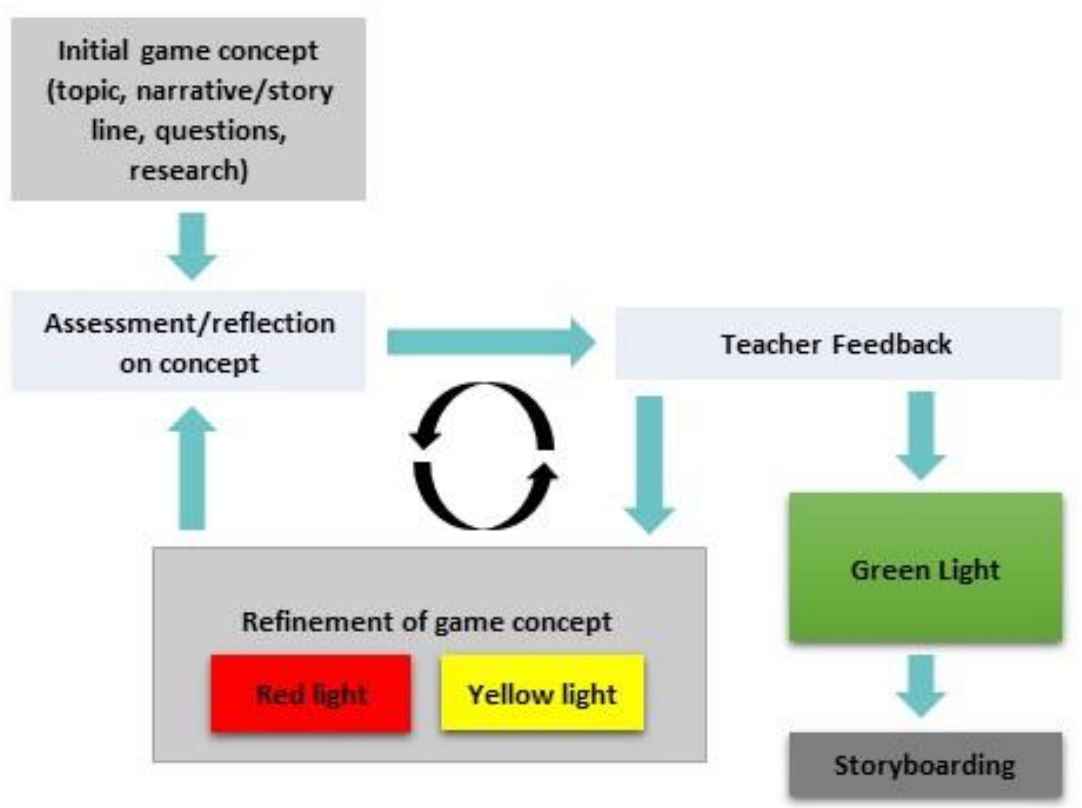

Figure 5. Formative assessment/reflection/feedback/refinement within game concept development task

As groups presented their developing game concepts for green, yellow or red lights, the goal was to provide feedback for improvement and to promote the effectiveness of the task's activities and by extension, the instructional and game design principles (Tables 4 and 5), in helping students/groups solve the given problem and achieve the learning and intervention goals.

A green light meant that the game concept was very informative and interesting and strongly supported the curriculum content in showing how the citizens in students'/groups' various models participated in the government decision-making process and some initial evidence of game design principles. A yellow light meant that the game concept revealed an insufficient amount of the curriculum content to show 
how the citizens in students'/groups' various models participated in the government decision-making process and little evidence of game design principles. A red light meant that the game concept revealed no evidence of the curriculum content to show how the citizens in students'/groups' various models participated in the government decision-making process and very little evidence of game design principles.

This formative assessment strategy, which also informed the ongoing analyses of the students'/groups' activities for improvement and was leading to iterations of their game concepts, included weekly assignments in Edmodo, frequent instructional conversations between practitioners and researcher, discussions and/or Socratic dialogues/questioning between practitioners and student group members, which also involved a great amount of coaching and scaffolding with teacher feedback, and peer and self-assessments with feedback. In this formative assessment strategy, students/groups were given opportunities to articulate or explain, debate, defend and reflect on their game concept ideas in an effort to stimulate critical and deeper thinking and learning of how the citizens in their various models participated in the government decision-making process.

After the first formative assessment, ten groups obtained a green light, but still needed to refine the presentation of their concepts in terms of clarity for easy understanding, while eight groups obtained a yellow light and two, a red light. The practitioners continued to coach and mentor, and formatively re-assess the groups that had received the yellow and red lights as they refined the content for their game concepts until they received green lights.

In reflecting on the groups' performance in the entire game concept development task, the practitioners indicated that some groups became overly focused on the details that led to the problem and were creating game concepts that had nothing to do with the government decision-making process in their models. One of the practitioners also reiterated the iterative nature of the task in helping their students design and construct strong game concepts to inform a deeper understanding of how the citizens in their various models participated in the government decision-making process as well as the design and building of the games at the potential players' skills level. By session 14 , and after three iterations of the game concept development task, all groups had obtained a green light to begin storyboarding their game concepts.

\subsubsection{Storyboarding task}

The main goal for the storyboarding task was for all groups to sketch and organize their game concepts into a sequence of elements that would function as a road map to the actual building of their game prototypes. In doing so, they would aim to communicate a deeper 
understanding of how the citizens in their various models participated in the government decision-making process, while also being intellectually engaged and developing their use of 21st century competencies. To initiate the storyboarding task, the practitioners presented all groups with the following plan (Figure 6).

Define storyboard and provide examples to students in 30-minute teaching moment.

Brainstorm and discuss storyboard ideas based on narratives/storylines using

questions to consider the rules and structure of the games.

Create storyboards using chosen medium-paper, iPads.

As an assignment, submit storyboards through Edmodo for teacher feedback and approval.

Finalize storyboards.

Figure 6. Initial storyboarding plan

Although some groups had begun planning and discussing their storyboard ideas after receiving their green light by session 9 in the game concept development task, the practitioners collaboratively initiated the storyboarding task in a 30-minute teaching moment with two classes per session (50 students - classes 6.1 and 6.3; classes 6.2 and 6.4) to explain and discuss the task's activities that had to be completed in creating or designing and constructing the storyboards. In doing so, they also provided storyboard examples of published games, such as Star Wars to help clarify and visualise the storyboard concept. Subsequent to this teaching moment, all groups became fully engaged in brainstorming ideas for their storyboards based on their game concepts and discussing the various responsibilities for their roles in the group.

As some of the groups created their storyboards, particularly in sessions 5 and 6 , it became evident to both practitioners and the researcher that in some groups, members seemed to be encountering difficulty with their role-associated responsibilities - some students appeared to feel that they could more effectively contribute to the creation of the storyboard in a different role or assisting in other roles. As a result, group members discussed and switched roles, as well as engaged in performing dual roles, which was possible, since in each group, there were members who were multi-skilled in most of the roles, as indicated in the My Learner Profile survey results. Later on, in the post interview, the students expounded on this experience as one of the ways they developed problem-solving skills without the teachers' assistance.

By sessions 7 and 8, the practitioners began assessing each group's storyboard using a similar formative assessment strategy (Figure 7) as was done in the game concept development task, with additional 
given opportunities to articulate or explain, debate, defend and reflect on their roles, various technologies and game design principles. As groups presented their developing storyboards for green, yellow or red lights, the goal was to provide feedback for improvement and to promote the effectiveness of the task's activities and, by extension, the instructional and game design principles in helping students/groups solve the given problem and achieve the learning and intervention goals.

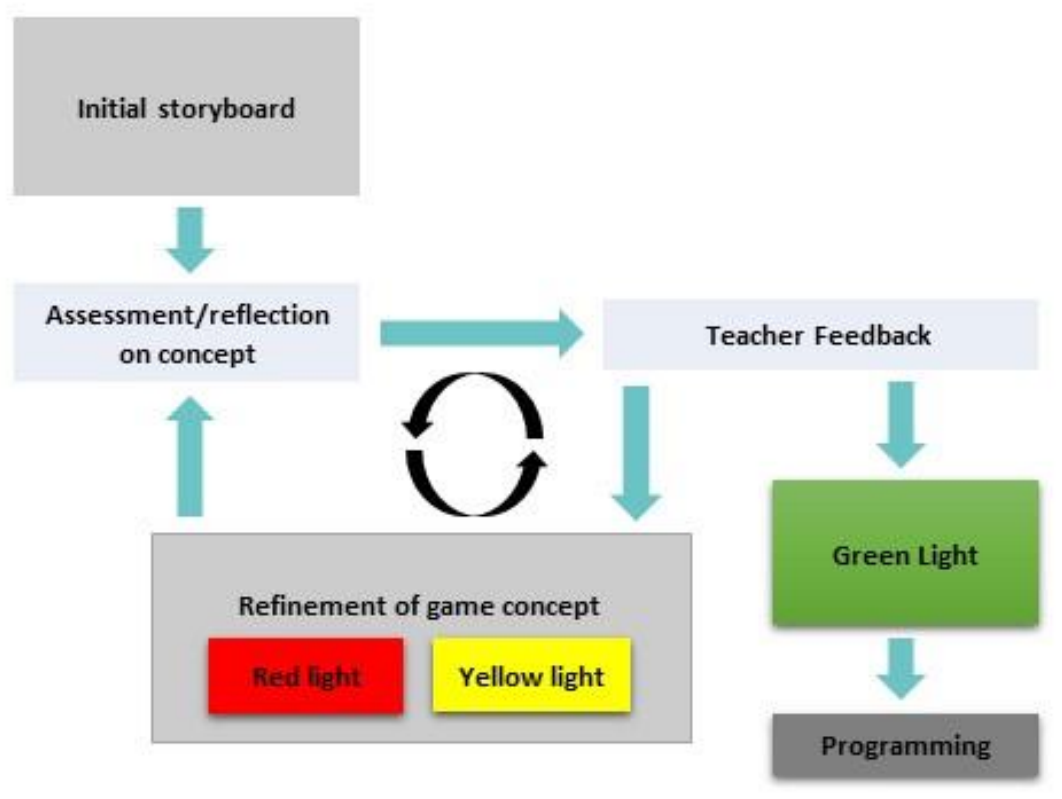

Figure 7. Formative assessment/reflection/feedback/refinement within storyboarding

After the first formative assessment of the storyboards was completed, in sessions 7 and 8, only five groups received a green light for their storyboards, but it was, according to the practitioners, 'under stipulation', which meant they needed to refine and reduce some of the overwhelming activities in the content. Thirteen groups received a yellow light and two a red light. The practitioners seemed very concerned with the lack of sufficient detail on how the citizens in students'/groups' various models participated in the government decision-making process in the content of the storyboards - groups were not using their research-informed game concepts as effectively as they could.

Therefore, the practitioners and researcher engaged in some formative evaluation of this issue and realized that the students/groups needed more guided instruction or coaching in incorporating the curriculum content from their game concepts into their storyboards than initially planned and given. Therefore, in sessions 9 and 10, the practitioners refined or re-designed the activity, resulting in the first iteration of this task. They provided some guided instruction, in a 30-minute teaching moment to all the groups, on how to incorporate the curriculum content from their game concepts into 
the storyboards and continued with further discussions and coaching, with detailed feedback, to assist individual groups in making the content of their storyboards more indicative of their level of understanding of the topic than just a game for kids to play.

As groups refined their storyboards based on teacher feedback, the practitioners formatively evaluated the types of activities that they had initially planned to help students/groups continuously refine their storyboards in order to reflect or communicate their deep understanding of how the citizens in their various models participated in the government decision-making process. They realized that students/groups needed more authentic opportunities, within and across groups, to think about, assess and refine their storyboards to reflect that deep understanding. Therefore, they refined or redesigned the plan to include self and peer assessment opportunities, resulting in a second iteration of this task.

In sessions 11 and 12, the practitioners utilized what they termed an 'elevator pitch' in order to help each group member to deeply reflect and self-assess the strengths and/or weaknesses of the design and content of their group's storyboard. This 'elevator pitch' was guided by the following questions:

1. What information does your player learn by playing your game?

2. What are the strengths and weaknesses of your game's content?

3. Does your game's content accurately reflect your own personal understanding of the topic? Explain.

Students were instructed to choose only one of these questions to answer in a one-minute video recorded on their iPads, which, when submitted received teacher feedback, along with a grade, on the details and explanations given, as well as on how well they articulated the ideas they shared with their teachers. Based on the feedback provided by the practitioners, they were quite impressed with each student's performance in terms of the detailed and honest explanations they provided, as well as the articulation of their ideas. Students used their reflections on the videos and feedback from their teachers to inform the continued refinement/iterations of their storyboards.

In sessions 15 and 16, the practitioners provided groups with the opportunity to share and assess their storyboards, across groups and classes, for feedback from their peers by allowing all groups to participate in 'group-share reflections' - groups were purposefully paired to review and provide constructive criticism and feedback to each other on their storyboards. From classes 6.1 and 6.3 , and 6.2 and 6.4 , respectively, the two girls' groups; two boys' groups, groups' $3 \mathrm{~s}$, $4 \mathrm{~s}$ and $5 \mathrm{~s}$ were paired for this activity. The group-share reflections were guided by two questions:

1. What are we going to learn as a user of this game? 
2. Is the storyboard focused on decision-making or on something else?

At the end of the group-share reflections, the practitioners assessed each individual student in terms of his/her positive contribution to the group-share reflection experience:

You are going to take one minute to think, out of the 9 other people, who do you feel ... really tried hard to make this a valuable experience? What we're going to do is when I start counting down from 5 , you got to make up your mind. When I get to zero, you're not going to say anything, but you're just going to point your finger at the person you really think stood out as somebody positive in this process. If you have no fingers pointed at you, that's an issue. If you have a finger pointed at you, good for you. (Conversation with groups in group share reflection session).

This process offered an informal way of peers assessing each other's contribution within and across groups and providing accountability on the four attributes: Cooperation, Contribution, Communication and Collaboration. Students felt it was a fun way to assess each other's performance. Using the feedback from their teachers, videos (selfassessments) and group-share reflections, all groups continued to refine their storyboards. By sessions 17 and 18, and after two iterations of this task, all groups had received the green light for their storyboards to move to the programming task. In concluding the storyboarding task, the practitioners reminded all groups that their storyboards were just theories of what they wanted their games to look like, and there was a possibility for them to change or be modified as the programmers coded the games.

\subsubsection{Programming Task}

The goal of the programming task was to allow students/groups to bring their game concepts/storyboards to life, while achieving the learning goals of the curriculum unit and intervention goals. In preparation for the programming of the games, using the iMacs in the library, the programmers from each group were given 35-minute warm-up sessions with Scratch, during which they tested the software by coding very simple animations.

Meanwhile, other group members, in the classrooms (downstairs), collaborated to discuss and plan their specific contributions, based on the storyboards, to the programming of their games. Then in the first session of the programming task, as presented in the plan in Figure 8 , the practitioners collaboratively held an introductory 15-minute teaching moment with two classes per session ( 50 students - classes 6.1 and 6.3; classes 6.2 and 6.4) to explain the task's activities that needed to be completed to program students'/groups' game concepts. 
Programmers given 35-minute warm-up sessions in Scratch on iMacs.

Programmers manage the coding of games in $\mathbf{3 5}$ and $\mathbf{3 0}$-minute sessions using storyboards as road maps or blueprints.

Rules, challenge, rewarding system/short feedback cycle, engagement/immersion, adaptability/flexibility, re-playability, competition/collaboration and fun should be built into the prototype.

Teacher feedback on progress and peer assessment/feedback provided as games are coded and built.

Changes or modifications made as games are created/built and tested informed by trial and error and feedback from group members.

Complete prototype 1.

Test and Tryout to ensure that prototype 1 matched players' skill level and usability; and modify as necessary.

Usability will include the game being easy to use so that the player can focus on the objectives of the game with no frustration; game functionalities easy to learn; no errors in interactions and navigation; inclusion of a user guide, tutorial or helpful prompts/hints.

Teacher and group reviews are provided on prototype 1.

As an assignment, group members will provide final reflection on contribution to the whole process.

Figure 8. Programming plan

Subsequent to the teaching moment, the practitioners used a more hands-off approach in the programming task. One of the practitioners explained that this approach resulted from the fact that they were not as skilled in using Scratch as their students and it was to encourage a more authentic collaborative experience for the students. As such, the programming task was more student-centred and managed. The practitioners mainly focused on ensuring that the groups' members in the classroom remained on-task. They also provided some constructive criticism and guidance to group members as they engaged in their specific roles, to prepare and submit the information (art, dialogues and music/sounds informed by the storyboards) needed by their programmers to code and build the games.

During the initial sessions of the programming task, it became obvious that the distance between the programmers in the lab and their group members in the classrooms seemed to pose a challenge to their communication and collaboration. Groups, therefore, used creative measures to address this challenge by setting up web conferencing via FaceTime and using iMessages to communicate and collaborate with their programmers. In the first two sessions, these forms of communication seemed to work, but groups began encountering difficulty with their connections and decided on another way to work with their programmers. Depending on the activity, the group member would join the programmer to collaboratively work on that activity. 
For instance, when the programmers were focused on drawing the backgrounds, characters and other visuals, the artists would join the programmers to complete that activity, and so on. This form of communication and collaboration continued throughout the programming task (42 sessions within an 8-week period), but groups continued to be challenged by the lab-classroom distance.

As programmers continued to build and test the first prototypes of their games, guided by the game design principles, they heavily depended on a peer assessment/reflection/feedback/test/refinement strategy (Figure 9), which informed the ongoing analyses of the students'/groups' activities and was leading to iterations of their game prototypes.

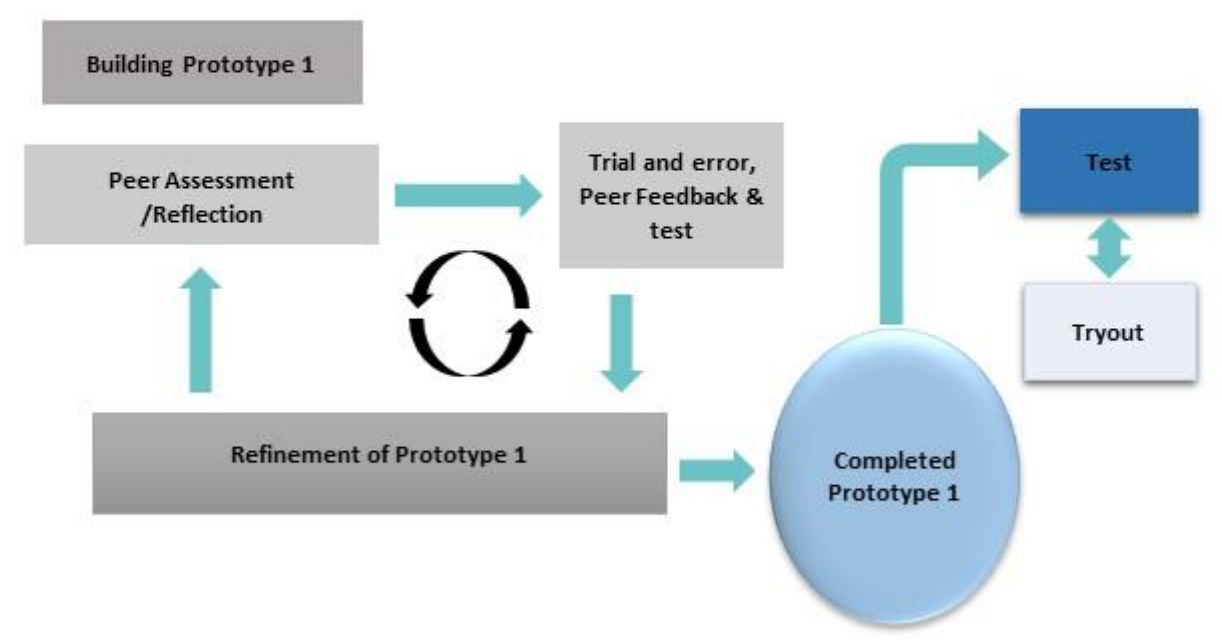

Figure 9. Peer assessment/reflection/feedback/test/refinement within programming task

By sessions 19 and 20, two weeks away from the stipulated deadline to complete their games, the status of all of the game prototypes indicated that none of the groups were near completion of prototype 1. Programmers complained that the 30 and 35 -minute sessions were insufficient in meeting that deadline. The practitioners, with the assistance of the school's professional development leader, discussed and evaluated this and other issues, for example groups' access to more hardware and the distance between the programmers and their group members. They addressed these issues by increasing the amount of time from 30 and 35-minute to one-hour sessions, provided reserved laptops from the library to accommodate this increased time so that 10 programmers could work per session with all their group members, instead of the original five, by themselves, and extended the deadline for completion of, at least, the first prototype by two weeks. These resulted in the first and only iteration of the design of this task.

Despite their challenges, groups were motivated to complete prototype 1 and some programmers worked extra hours at home. By sessions 41 and 42 , three groups completed the first prototype of their 
games, while others were about $80-90 \%$ complete. The three groups tested and tried out their prototypes with their peers, within and across groups, practitioners and researcher, mostly for their usability - the game being easy to use so that the player can focus on the objectives of the game with little or no frustration; game functionalities easy to learn; no errors in interactions and navigation; inclusion of a user guide, tutorial or helpful prompts/hints and matching players' skill level. It became obvious that there were a few glitches that needed to be fixed before the prototypes could be reviewed for further refinements or iterations.

To complete their implementation of the learning tasks, the practitioners summatively assessed individual students' overall performance within all the learning tasks by using a final reflection rubric, guided by the following questions:

1. How did you feel when you first received your assignment? Why?

2. How has your understanding of the role changed over time?

3. What was one area of challenge relating to your role that you overcame?

4. How did you move past this challenge?

5. How does your final product reflect your skill and expertise regarding your role?

6. What are you most proud of in your final game?

7. If you could go back and do it all again, what would you do differently in your role?

8. How effective have you been in your assigned role for your Scratch group?

\subsection{Assessment Phase - Evaluation and Reflection}

The assessment phase or evaluation and reflection phase "constitutes one (empirical) micro-cycle" (McKenney \& Reeves, 2012, p. 80) and represents the final phase of the DBR process. The purpose of this phase, as employed in this research study, was to assess/evaluate and reflect on (i) the potential and effectiveness of the design and building of video games as an innovative pedagogy that could intellectually engage students in deep learning of curriculum content and promote their development and use of 21st century competencies, thus attempting to address one of the main challenges faced by $\mathrm{K}-12$ educators and the problem that initiated this study; and (ii) its effectiveness in possibly addressing some of the concerns/unplanned effects and gaps identified in past research studies, in and beyond the school context. This assessment/evaluation and reflection were informed by the findings resulting from its exploration in the prototyping phase of the DBR process. 
In addressing the research questions, findings resulting from the analysis of the data collected during the implementation of this intervention seemed to reveal its impact on teacher practice, some emerging theoretical support and student deep learning, intellectual engagement and development of 21st century competencies.

\subsection{Impact on Practice}

DBR advocates contend that research should refine theory and practice (Collins \& Bielaczyc, 2004). Findings indicated that practice was refined as practitioners refined the instructional activities and their design principles in order to meet student learning and intervention goals. This refinement of practice represented a shift from their normal design of instructional activities to teach the same content in their social studies classes. Some examples included: (i) employment of more interaction modes to collaborate and communicate during tasks' activities (Figure 10); (ii) use of more extensive coaching and scaffolding (Figure 11); (iii) continuous use of various forms of context-specific assessments (for, as and of learning) with feedback loops (Figure 12) that also reflected the context and the nature of their students, and that deliberately developed and adapted as the process continued to assess students' progress; and (iv) use of more extensive conceptual and divergent thinking to ensure that students were demonstrating their deep understanding of their chosen topics and were not just focused on creating a game. Teachers indicated that these instructional and design experiences did provide them with meaningful professional development experiences to meet the learning needs of present and future students in this changing teaching and learning environment.

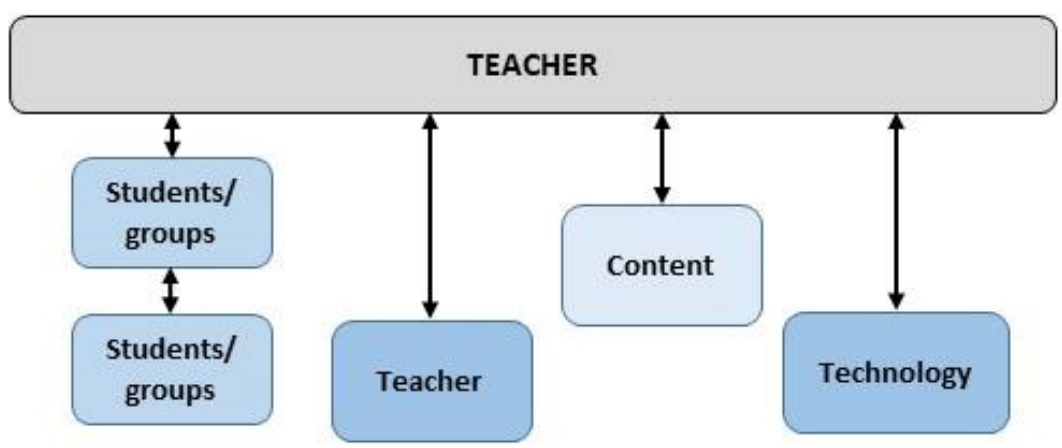

Figure 10. Interaction modes for collaborating and communicating during learning tasks, adapted and modified from Moore's (1989) three types of interactions in an online course 


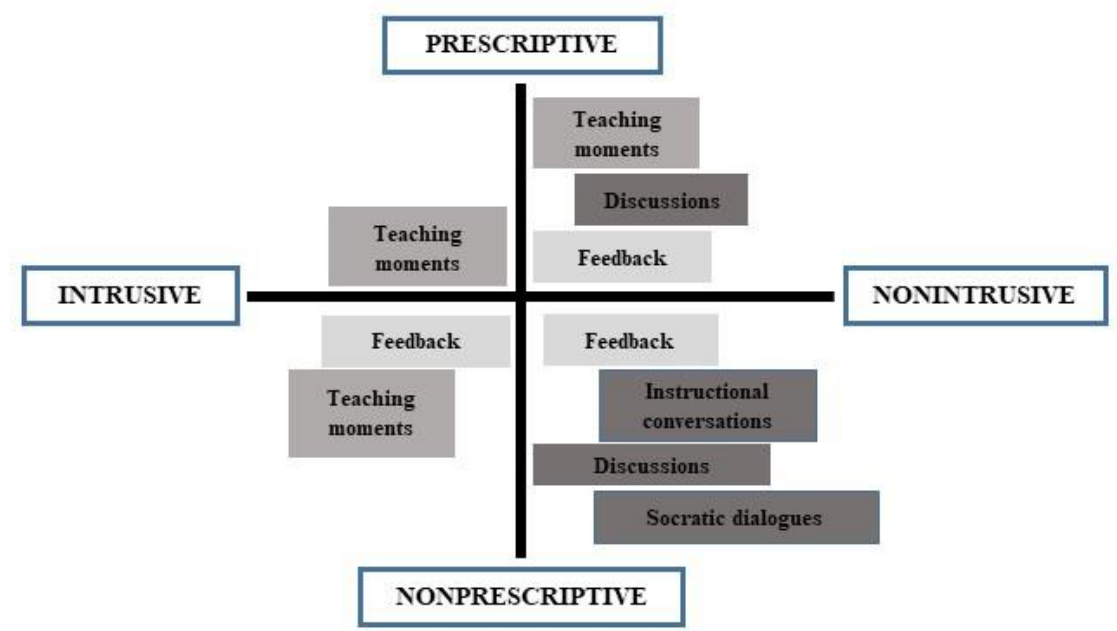

Figure 11. Coaching and scaffolding model during implementation of learning tasks, adapted from Cates and Bruce's (2000) model of scaffolding

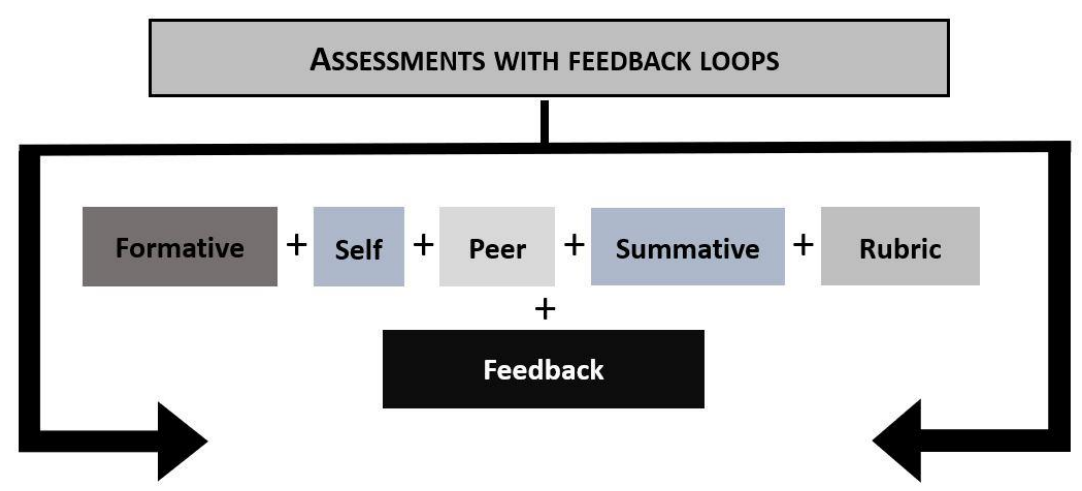

Figure 12. Forms of assessments and feedback loops used in the practitioners' design of instruction during implementation of learning tasks

\subsection{Theoretical Impact}

Theory refinement was not as evident in this short-term study because, as explained by Amiel and Reeves (2008), "this might only occur after long-term engagement and multiple design investigations" (p. 35). Therefore, for theory development and refinement to support practice, further research involving the design and implementation of this intervention using more meso-cycles of the prototyping phase is needed. What was apparent, however, was the presence of other underlying learning theories supporting the practitioners' design and implementation of the tasks' activities. In addition to situated learning theory, which informed the theoretical framework for the design and implementation of the learning tasks constructivist ideas and students' creation of their new knowledge, and game design theory through game design principles, it became evident that other learning theories including constructionism, connectivism, assessment theory and scaffolding theory seemed to be supporting and describing the instructional design, pedagogical approach and student learning. 
Constructionism was evident as practitioners encouraged students/groups to collaboratively construct their new knowledge/ideas, in the game concept and storyboarding tasks, through inquiry/learning, discussions, brainstorming, research, invention and personal reflection (Papert, 1991) and then to effectively use their knowledge/ideas to build their own video game prototypes in the programming task. Connectivism became evident as the practitioners linked students/groups to their peers/groups and resources (Edmodo, hardware, game software/Scratch, SMART board, videos, blogs, iMessage, and so on) to collaborate, communicate, support and share their learning and growing understanding of how the citizens in their various models participated in the government decision-making process.

Assessment theory, more specifically, assessment for, as and of learning was evident as practitioners assessed student learning and progress in each learning task. Assessment for learning (Black, Harrison, Lee, Marshall \& Wiliams, 2003; Earl, 2012; Taras, 2010) was exemplified as practitioners embedded continuous formative assessments in the tasks' activities to assess students'/groups' progress, promote student learning and inform refinements to the instructional and learning tasks' activities to meet students' learning needs. Assessment as learning (Earl, 2012) was evident, in practice, as students' engaged in self and peer assessments (Let's Reflect rubric, students'/groups' reflections in their Kidblogs, elevator pitches and group-share reflections with feedback for improvement), to assess their own learning as well as to promote their confidence and selfesteem through an understanding of how they learned. Assessment of learning (Black, 1998) was evident as individual students were summatively assessed on their contributions to meeting the learning goals through their assigned roles; progressive understanding of their roles throughout the whole process; challenges encountered through their roles and how they addressed those challenges to meet the learning goals; and what they would change in their assigned roles to meet the learning goals given the opportunity to participate in another project involving this intervention. Scaffolding theory was also evident in teachers' extensive use of coaching and scaffolding, during the game concept development and storyboarding tasks, as students required additional guidance and support to develop their game concepts and create and design their storyboards to inform the building of their video games.

\subsection{Impact on Student Deep Learning}

Findings indicated that deeper learning of the curriculum content seemed most evident in the learning tasks as all students/groups collaboratively brainstormed story ideas, formulated effective questions, researched the curriculum content, discussed, debated, reflected, developed their game concepts and storyboarded them, and 
while building their game prototypes [emphasis added]. Deep learning of role-specific skills and game design principles also seemed to be most evident as students/groups storyboarded their game concept ideas. Practitioners, however, stated that a deep learning of the curriculum content was not as evident or visible in the resulting draft game prototypes (for example, Figure 13). Overall, the storyboarding task was observed to represent the area of deepest learning of the curriculum content, while the programming task seemed to represent the area of deepest learning about the game design principles and Scratch.
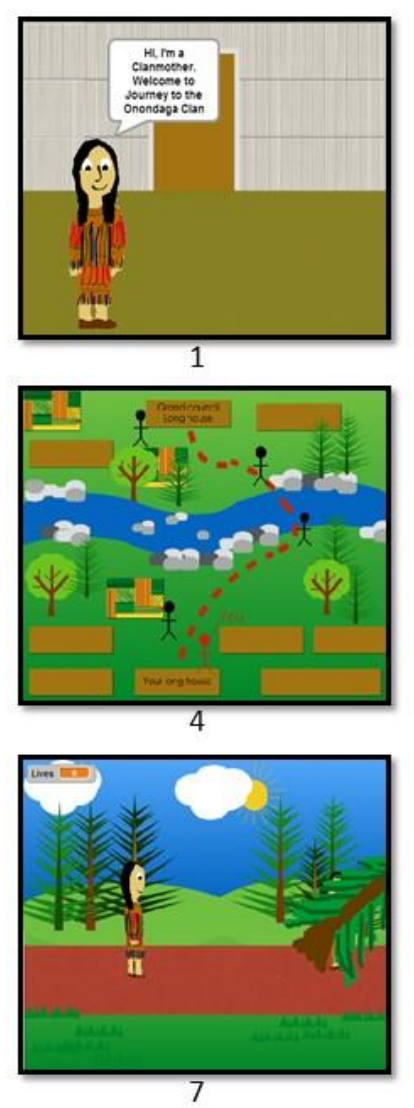
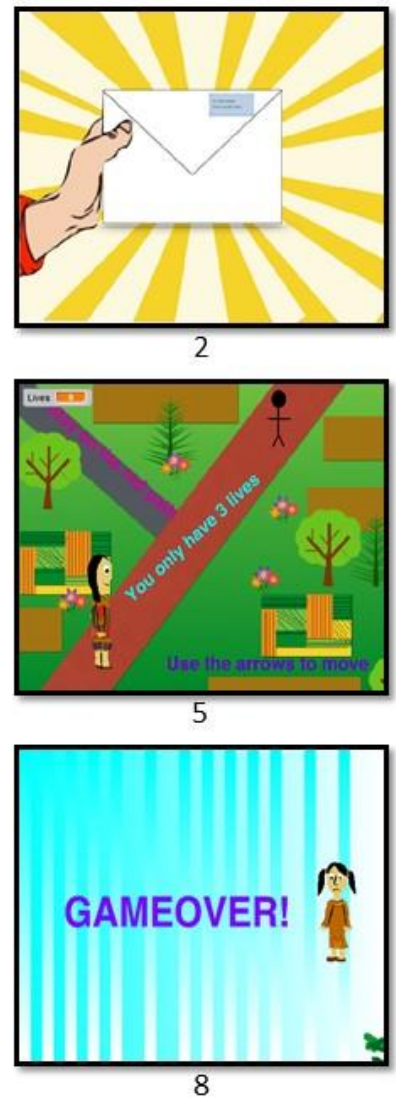
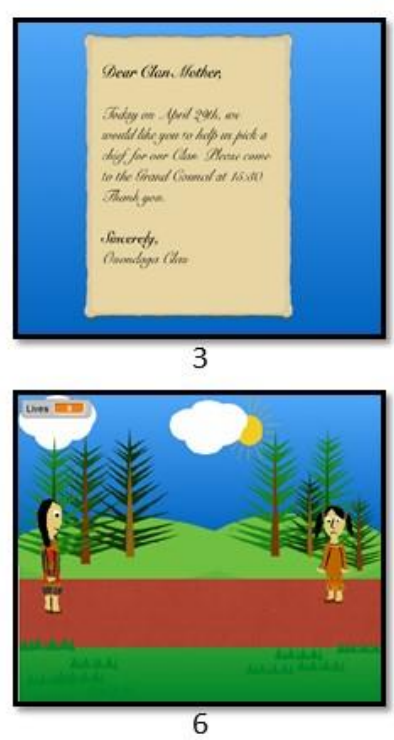

Figure 13. Video game prototype 1 scenes from Journey to the Onondaga Clan

\subsection{Impact on Student Intellectual Engagement}

Findings indicated that as students/groups participated in the learning tasks' activities to create new knowledge (game concepts, storyboards and game prototypes), intellectual engagement was clearly evident throughout this experience, but highest during the storyboarding task. Findings also revealed that there was a reciprocal relationship between the intellectual engagement themes (flow, motivation, effort, enjoyment, interest and relevance), as one depended or led to the other in students' intellectual engagement experiences. About 92\% of the students/groups interviewed indicated that their interest was highly sustained by the relevance of the learning tasks' activities 
to future roles in their own lives. All students/groups indicated that high interest and relevance motivated them to complete the storyboarding task, compared to $79 \%$ for the programming task, despite the many challenges they encountered as they performed their role-specific activities. That interest, motivation and effort helped about $83 \%$ of students/groups to experience that flow state leading to their complete involvement, focus and concentration, to the point where they lost track of time and had fun and enjoyed participating in the tasks' activities. Practitioners stated that intellectual engagement functioned as an inherent feature of the overall game design and building process.

\subsection{Impact on Student Development of $21^{\text {st }}$ Century Competencies}

Findings indicated that all students seemed to become even more proficient and skilled in all of the 21st century competencies as their learning continued through the storyboarding and programming tasks. Findings also revealed that these competencies seemed to help promote students' deep learning of the curriculum content and other emerging content in the process at the same time - reciprocal relationship. This helped students to be engaged in the ways in which they will be expected to engage as citizens in a knowledge-building society. Practitioners also stated that, like intellectual engagement, development of 21st century competencies seemed to be an inherent feature of the overall game design and building process.

\section{Conclusion}

Our collective need for innovative solutions in education and responsive designs for deep learning in diverse contexts is on the rise as the problems and issues that challenge education and the teaching profession become increasingly complex (Friesen \& Jacobsen, 2015). DBR is "a commitment to understanding learning and instruction in authentic contexts ... and provides a useful framework for studying learning in existing classrooms" (Squire, 2005, p. 11). There is often a gap between the practices of classroom teachers in the complex and real-world learning environments in schools, and the educational theory and research on learning pursued by university researchers. As a participatory educational research methodology, DBR can help to reveal what, how, when, and why interventions work through an iterative design and evaluation process, and sustained collaboration between practitioners and researchers, leading to "a better understanding of the process of intervention" (Amiel \& Reeves, 2008, p. 35). DBR serves as one response to addressing the gap between theory and practice in educational research, and the persistent call for change and innovation in education systems (Jacobsen, 2014). This DBR study represented such a sustained commitment to innovative pedagogies and learning by two grade 6 practitioners and their 
students, in collaboration with a university research team, to reveal how the design and building of digital video games could be enacted in classroom teaching and learning for more innovative and authentic student learning and design-based pedagogical practices.

Findings emerging from this DBR study indicated that for teachers to effectively implement the intervention in the classroom context, they needed theory and research-informed designs, and pedagogical and research support in shifting/modifying their design of instructional activities compared to how they would normally design them in their social studies classes to teach the same chosen content. With the support of the research team, and through access to data to inform instruction designs and decision-making, the practitioners engaged in highly reflective pedagogical conversations and engaged in new assessment and feedback pedagogies, mentoring and coaching approaches, and design-based learning processes with their students. Findings also revealed that the intervention, as implemented and studied, seems to have the potential to be an effective innovative strategy/pedagogy for deep learning and one that promotes the intellectual engagement of students and their development and application of 21st century competencies. Future iterations/refinement of this intervention are needed for possible long-term effectiveness and validation of its usability and impact in similar and other educational contexts and/or disciplines.

Among the many implications of these findings for K-12 educators, school jurisdictions and Alberta Education, the following must be noted for the implementation of interventions in school: (i) using design-based interventions that have the potential to transform the classroom environment into places of effective teaching and learning practices which challenge students' ideas and support them in making connections between the curriculum content and real life/world situations; (ii) assessing the type of theoretical support needed for the effective implementation of interventions as pedagogical designs; (iii) using DBR as an effective framework to study how interventions can create more visible, relevant, interesting, engaging and authentic teaching and learning experiences in school, for a more connected and complex world; and (iv) the development of policy for the implementation of interventions that will "foster sustainable change across whole systems to achieve deep learning aims" (Fullan \& Langworthy, 2014, p. iii) and provide design-based professional learning opportunities for teachers, such as this one and those described by Friesen and Jacobsen (2015), and other leaders to ensure that they embrace technological change, participate in the integration of technology into formal classroom teaching and learning and address concerns about e-safety, resources, logistics and sustained innovation. 
Alberta Education. (2007). Social studies (K-12). https://education.alberta.ca/media/774369/ss6.pdf

Amiel, T., \& Reeves, T. C. (2008). Design-based research and educational technology: Rethinking technology and the research agenda. Educational Technology \& Society, 11(4), 29-40.

Anderson, T., \& Shattuck, J. (2012). Design-based research: A decade of progress in education research? Educational Researcher, 41(1), 16-25.

Bereiter, C. (2002). Education and mind in the knowledge age. Routledge.

Binkley, M., Erstad, O., Herman, J., Raizen, S., Ripley, M., \& Rumble, M. (2010). Draft white paper 1: Defining 21st century skills. http://atc21s.org/wp-content/uploads/2011/11/1-Defining-21stCentury-Skills.pdf

Black, P. (1998). Testing: friend or foe? Theory and practice of assessment and testing. Falmer Press.

Black, P., Harrison, C., Lee, C., Marshall, B., \& Wiliams, D. (2003). Assessment for learning. Putting it into practice. Open University Press.

Boud, D., \& Knights, S. (1996). Reflective learning for social work: Research, theory and practice. In N. Gould \& I. Taylor (Eds.), Reflective learning for social work: Research, theory and practice (pp. 23-34). Ashgate.

Bransford, J. D., Vye, N., Kinzer, C., \& Risko, V. (1990). Teaching thinking and content knowledge: Toward an integrated approach. In B. F. Jones \& L. Idol (Eds.), Dimensions of thinking and cognitive instruction (pp. 381-413). Lawrence Erlbaum.

Brown, J. S., \& Adler, R. P. (2008, January/February). Minds on fire: Open education, the long tail, and learning 2.0. EDUCAUSE Review 43(1), 16-32.

Cates, W. M., \& Bruce, R. R. (2000). Conceptualizing learner support space. Educational Technology Research and Development, 48(1), 85-98.

Collins, A., Joseph, D., \& Bielaczyc, K. (2004). Design research: Theoretical and methodological issues. The Journal of the Learning Sciences, 13(1), 15-45. 
Creswell, J. W. (2014). Research design: Qualitative, quantitative and mixed methods approaches (4th ed.). SAGE Publications, Inc.

Csikszentmihalyi, M. (1990). Flow: The psychology of optimal experience. Harper and Row.

Daniels, J., Jacobsen, M., Varnhagen, S., \& Friesen, S. (2013). Barriers to systemic, effective and sustainable technology use in high school classrooms. Canadian Journal of Learning and Technology, 39(4).

Dunleavy, J., \& Milton, P. (2009). What did you do in school today? Exploring the concept of student engagement and its implications for teaching and learning in Canada. Canadian Education Association (CEA), 1-22.

Dunleavy, J., Milton, P., \& Willms, D. (2012). Trends in intellectual engagement. What did you do in school today? (Research Series Report Number Three). Canadian Education Association.

Earl, L. (2012). Assessment as learning: Using classroom assessment to maximize student learning (2nd ed.). University of Toronto Press.

Friesen, S., \& Jacobsen, M. (2015). A design-based approach to teachers' professional learning. Canadian Education Association Blog [Web log comment]. https://www.edcan.ca/articles/a-designbased-approach-to-teachers-professional-learning/

Fullan, M., \& Langworthy, A. (2014). Rich seam: How new pedagogies find deep learning. Pearson.

Gagné, R. M., Briggs, L. J., \& Wager, W. W. (1992). Principles of instructional design (4th ed.). Harcourt Brace Jovanovich College Publishers.

Herrington, J., \& Oliver, R. (2000). An instructional design framework for authentic learning environments. Educational Technology Research and Development, 48(3), 23-48.

Herrington, J., \& Reeves, T. C. (2011). Using design principles to improve pedagogical practice and promote student engagement. In G. Williams, P. Statham, N. Brown \& B. Cleland (Eds.), Changing demands, changing directions (pp. 594-601). Proceedings ascilite Hobart.

Hung, W. (2006). The 3C3R model: A conceptual framework for designing problems in PBL. Interdisciplinary Journal of Problembased Learning, 1(1), 55-77. http://docs.lib.purdue.edu/cgi/viewcontent.cgi?article=1006\&cont ext=ijpbl 
Jacobsen, M. (2010). Teaching in a participatory digital world. Education Canada, 50(3), 13-17.

Jacobsen, M. (2014). Design-based research: Sponsoring innovation in education. Education Canada, 54(5), 22-24. https://www.edcan.ca/articles/design-based-research/

Jacobsen, M., \& Friesen, S. (2011). Web exclusive: Hands on vs. hands up: Technology-enabled knowledge building in high school. Education Canada, 51(3).

Jenkins, H., Puroshotma, R., Clinton, K., Weigel, M., \& Robison, A. J. (2006). Confronting the challenges of participatory culture: Media education for the 21st century. The MacArthur Foundation.

Junco, R., \& Mastrodicasa, J. (2007). Connecting to the net.generation: What higher education professionals need to know about today's students. Student Affairs Administrators in Higher Education (NASPA).

Lacey, A., \& Luff, D. (2001). Trent focus for research and development in primary health care: An introduction to qualitative analysis. Trent Focus. United Kingdom.

LiteracyResearch. (2014, April 8). LRA research to practice episode 6 Design-based research [Video file]. https://www.youtube.com/watch?v=vplVyUxVE8E

McKenney, S. E., \& Reeves, T. C. (2012). Conducting educational design research. Routledge.

McLoughlin, C., \& Oliver, R. (2000). Designing learning environments for cultural inclusivity: A case study of indigenous online learning at tertiary level. Australian Journal of Educational Technology, 16(1), 58-72.

Mellini, B., Talamo, A., \& Giorgi, S. (2010). ProActive: Fostering teachers' creativity through game-based learning. http://www.ub.edu/euelearning/proactive/documents/proActivepsycho-pedagogical-framework.pdf

Millar, E. (2015). The learning puzzle. Deeper than knowledge. http://deeperthanknowledge.com/

Moore, M. G. (1989). Three types of interaction. The American Journal of Distance Education, 3(2), 1-6.

Moustakas, C. (1994). Phenomenological research methods. SAGE Publications. 
Oliver, R. (2000). When teaching meets learning: Design principles and strategies for Web-based learning environments that support knowledge construction. Proceedings of the Australian Society for Computers in Learning in Tertiary Education 2000 conference. Southern Cross University, Coffs Harbour, Australia.

Papert, S. (1991). Situating constructionism. In I. Harel \& S. Papert (Eds.), Constructionism (pp. 1-11). Ablex Publishing Corporation.

Rieber, L. P. (1996). Seriously considering play: Designing interactive learning environments based on the blending of microworlds, simulations, and games. Educational Technology Research and Development, 44(2), 43-58.

Ritchie, J., \& Spencer, L. (1994). Qualitative data analysis for applied policy research. In A. Bryman \& R. Burgess (Eds.), Analysing qualitative data (pp. 173-194). Routledge.

Squire, K. D. (2005). Changing the game: What happens when videogames enter the classroom? Innovate 1(6).

Tapscott, D. (2009). Growing up digital: How the net generation is changing your world. McGraw-Hill.

Taras, M. (2010). Assessment for learning: Assessing the theory and evidence. Procedia Social and Behavioural Sciences, 2(2), 30153022.

Wang, F., \& Hannafin, M. J. (2005). Design-based research and technology enhanced learning environments. Educational Technology Research and Development, 53(4), 5-23.

West-Burnham, J., \& Coates, M. (2005). Personalizing learning. Network Educational Press.

Willms, J. D., Friesen, S., \& Milton, P. (2009). What did you do in school today? Transforming classrooms through social, academic and intellectual engagement, first national report. Canadian Education Association. 
Dr. Deborah Lambert is an instructor of Learning Sciences, Graduate Programs, in the Werklund School of Education at the University of Calgary, Canada, Her scholarly interests are quite diverse and focus, both in research and practice, on advancing technologies, online instruction, game-based learning, program evaluation, collaborative teaching and learning, leadership, technology integration into teaching and learning environments, design-based research, action research, mathematics teaching and learning, cyberbullying, peer mentoring, and textbook publishing.

Michele Jacobsen is a full professor of Learning Sciences in the Werklund School of Education at the University of Calgary, Canada, who uses design-based, case study and action research to study innovative designs for learning and of participatory pedagogies for knowledge building and intellectual engagement in open learning environments. Her current research focuses on online faculty development for quality graduate supervision, interdisciplinary approaches to peer mentoring for strong transitions to graduate school, research-based learning in blended and online professional graduate programs, internet use by Canadian families, and leading complex adaptive learning systems in kindergarten to senior high schools. Michele has been recognized for leadership in higher education and for her commitment to creating engaging learning experiences and mentoring students with awards for excellence in leadership, teaching, and graduate supervision.

Dr. Deborah G. Lambert

Werklund School of Education

University of Calgary

2500 University Drive NW Calgary

Canada

(403) 220-5110

dglamber@ucalgarv.ca

Prof. Dr. Michele D. Jacobsen

Werklund School of Education

University of Calgary

2500 University Drive NW Calgary

(403) 220-5110

dmiacobs@ucalgarv.ca 
Prof. Dr. Tobias Jenert

Chair of Higher education and Educational Development

University of Paderborn

Warburgerstraße 100

Germany

+49525160-2372

Tobias.Jenert@upb.de

Journal Details EDeR-Educational Design Research

An International Journal for Design-Based Research in Education

ISSN: 2511-0667

uhh.de/EDeR

\#EDeRJournal (our hashtag on social media services)

Published by

Hamburg Center for University Teaching and Learning (HUL)

University of Hamburg

Schlüterstraße 51

20146 Hamburg

Germany

+49 $4042838-9640$

+49 $4042838-9650$ (fax)

EDeR.HUL@uni-hamburg.de

hul.uni-hamburg.de

In collaboration with

Hamburg University Press

Verlag der Staats- und Universitätsbibliothek Hamburg -

Landesbetrieb

Von-Melle-Park 3

20146 Hamburg

Germany

+4940428387146

info.hup@sub.uni-hamburg.de

hup.sub.uni-hamburg.de 